\title{
Feed Efficiency and Serobiochemical Profile of Wistar Rats Fed With Spirulina As Functional Food
}

\author{
K. MANJULA ${ }^{1 *}$, M. ALPHA RAJ ${ }^{2}$ and RAMYA KRISHNA ${ }^{3}$ \\ ${ }^{1}$ Food Science and Nutrition, Department of Home Science, College of Sciences, Sri \\ Venkateswara University, Tirupati, Andhra Pradesh, 517502 India. \\ 2Department of Veterinary Pharmacology and Toxicology, College of Veterinary Science, \\ Proddutur, Andhra Pradesh, 516360 India. \\ ${ }^{3}$ Food Technology, Department of Home Science, College of Sciences, Sri Venkateswara \\ University, rupati, Andhra Pradesh, India-517502. \\ http://dx.doi.org/10.12944/CRNFSJ.4.2.07
}

(Received: July 30, 2016; Accepted: August 21, 2016)

\begin{abstract}
Spirulina is an algae that grow in fresh and sea water and itself known to the human community with its unique Neutraceuticals properties, generally produced from the species named Arthrospira platensis, and Arthrospira maxima. Arthrospira species were cultivated throughout the world to fulfil the need of human dietary supplementation. An experimental study was planned to know the effect of spirulina supplementation on serum biochemical profile of Wistar albino rats as model study. Test results clearly denoted that diet planned with spirulina fed rats showed better serobiochemical profile when compared with stock diet and rice based diet. The protein and albumin values were significantly higher in spirulina fed rats. Feed consumption rate is very low in spirulina diet but gained more weight when compared to stock and rice diets, this might be due to high biological value protein in spirulina.
\end{abstract}

Key-words: Spirulina, Rice, Serobiochemical profile, Feed consumption, Feed efficiency.

\section{INTRODUCTION}

One of the most important research areas in the field of nutritional science is to investigate the role of dietary active compounds in human nutrition. Food and diet not only supply the nutrients to the body to perform its functions, but also have several beneficial effects to maintain the health. Several findings have implicated food as a major factor behind majority of the metabolic and degenerative diseases ${ }^{1}$. In recent years, researchers are identifying some of the specific bioactive components in food and assessing their mechanisms, role and effects within the body. Eating a diet high in refined carbohydrates in the form of white rice is appears to increase the risk of diabetes and coronary heart diseases.etc ${ }^{3}$.
Agribusiness decertifies the soil, reduces biodiversity, increases global warming and depletes food resources. Nutritionists and scientists have been searching the alternative resources, one such natural food is Spirulina, blue green algae with multi-nutrient contents, not only in abundance but also in balance ${ }^{4}$. Spirulina is emerging as an important therapeutic food because of its high concentration of functional components and has been studied extensively due to its therapeutic potential in several areas ${ }^{5}$. The key implications backed by scientific findings are as functional food and additives, antioxidant, anti-inflammatory, hypolipemic, anti-hypertensive, anti-diabetic, anti-cancer, immunostimmulant, antimicrobial, hepatoprotective, neuroprotective, anti-anaemic and anti-leucopenic and tissue engineering 6 . 
Being consumed since centuries, Spirulina has well established itself as a functional food against an array of nutritional deficiencies. In recent years, Spirulina has garnered enormous attention from research fraternity as well as food, pharma and neutraceutical industries ${ }^{6}$. In view of the inconclusive reports regarding benefits of Spirulina, an attempt was made to evaluate the efficacy of Spirulina diet in comparison with rice based and stock diet.

\section{Methodology}

A total number of 18 healthy albino Wistar rats of 21-25 days age were selected for the experiment. Rats were kept in polypropylene cages with 12 hour of dark and light cycle and maintained at normal and static laboratory conditions of temperature and relative humidity in the animal house of the department of Food Science and Nutrition, Sri Venkateswara University, Tirupati. They were initially fed with the feed procured from National Centre for Laboratory Animal Sciences, National Institute of Nutrition, Hyderabad. Rats were given ad-libitum feed and water during the period of acclimatization (one week).

\section{Experimental Design}

A randomized block design was adopted and a total of 18 rats were distributed into three groups. All the groups consists of six rats ( $n=6$, each) i.e. three male and three female. All the rats were kept individually in separate cages. An identification mark was given to each rat and tags were prepared with respective identification mark and attached to the cages.

\section{Experimental Diets}

Three diets with different composition of nutrients were planned which were the test diets for the study. Stock diet, Spirulina, Rice based diets are the test diets which were served to the group I(Stock diet), group II(Spirulina), and group III(Rice based diets) respectively. The diet composition is presented in table 1.

\section{Feed Consumption}

Animals in each group were fed with the respective diets every day. Individual daily food consumption record was maintained. The feed that is served to each animal was weighed and recorded. Split and leftover food was weighed everyday to obtain an accurate weight of the food consumed. The food consumed and leftover feed by the rats was calculated to obtain feed conversion rate (FCR).

$$
\begin{gathered}
\mathrm{FCR}=\text { Feed consumed }(\mathrm{gm}) / \text { Body } \\
\text { weight gain }(\mathrm{gm})
\end{gathered}
$$

\section{Feed Analysis}

All the experimental diets prepared were analyzed for proximate analysis. Analysis of dry matter, moisture, crude protein, ether extract, total ash and acid insoluble ash were analysed using standard food analysis techniques ${ }^{8}$.

\section{Biochemical Assays}

At the end of the experimental period $\left(6^{\text {th }}\right.$ week), animals were weighed and the readings were recorded. The blood was collected by retro orbital puncture in serum vaccutiners. The blood was

Table 1: Composition of the test diets per $100 \mathrm{gm}$

\begin{tabular}{lccccc}
\hline \multicolumn{2}{c}{ Stock Diet } & \multicolumn{2}{c}{ Spirulina Diet } & \multicolumn{2}{c}{ Rice Diet } \\
Ingredients & Quantity (gm) & Ingredients & Quantity (gm) & Ingredients & Quantity (gm) \\
\hline Wheat Rawa & 50 & Wheat Rawa & 50 & Rice & 90 \\
Sprouted green gram & 16 & Green gram dal & 15 & Red gram dhal & 4 \\
Amaranths & 16 & Amaranths and carrot & 16 & Brinjal & 2 \\
Carrot & 16 & Sugar & 15 & Plantain & 2 \\
Gingelly oil & 2 & Gingelly oil & 2 & Gingelly oil & 2 \\
Milk & $20 \mathrm{ml}$ & Spirulina & $2 \mathrm{gm}$ & - & - \\
\hline
\end{tabular}


allowed to settle for sometime in order to separate the serum and again it was centrifuged in order to obtain clear serum (9). This serum was used for analysis of various biochemical parameters like glucose, ALT, cholesterol, triglycerides, protein, albumin, urea, creatinine and calcium. The sero-biochemical parameters were estimated auto analyzer (model: Star 21 plus, Aspen Diagnostics Pvt. Ltd.).

\section{Statistical Analysis}

The data was analyzed by unvariate analysis, ANOVA, Tukey's HSD post-hoc using SPSS version 15.

\section{RESULTS AND DISCUSSION}

The results and relevant discussion on feed analysis and effect of the supplementation of Spirulina on feed efficiency and serum biochemical parameters of Albino rats are presented.

\section{Feed Analysis}

All the experimental diets prepared were analyzed for proximate values and are presented in Table 2. The data shows that Spirulina diet contains high amount of dry matter and acid insoluble ash when compared with stock diet and rice based diet. Spirulina itself contains an unusually high amount of protein depending upon the source. Spirulina contains all essential aminoacids, hence called as a complete protein. When compared to the animal proteins such as meat, eggs, and milk, spirulina has slightly lower concentrations of amino acids such as methionine, cysteine and lysine, but still it is superior to plant protein, and nearly three times higher than the protein of the ever popular soya bean ${ }^{10}$. Further

Table 2: Proximate analysis of experimental diets

\begin{tabular}{lccc}
\hline Nutrient & $\begin{array}{c}\text { Stock } \\
\text { Diet (\%) }\end{array}$ & $\begin{array}{c}\text { Spirulina } \\
\text { Diet (\%) }\end{array}$ & $\begin{array}{c}\text { Rice } \\
\text { Diet (\%) }\end{array}$ \\
\hline Dry matter & 58.72 & 95.1 & 79.29 \\
Moisture & 41.28 & 4.9 & 20.71 \\
Crude protein & 31.63 & 15.68 & 8.78 \\
Ether extract & 7.85 & 7.79 & 0.38 \\
Total ash & 7.28 & 7.91 & 1.97 \\
Acid insoluble ash & 2.25 & 2.09 & 0.55 \\
\hline
\end{tabular}

it is rich in linoleic acid, alpha linolenic acid, gammalinolenic acid, stearidonic acid, eicosapentaenoic acid, docosahexaenoic acid, and arachadonic acid. Spirulina also contains vitamin B1, B2, B3 , B6 , B9, $C, D, A$, and vitamin $E$. It is a rich source of minerals such as potassium, calcium, chromium, copper, iron, magnesium, manganese, phosphorus, selenium, sodium and zinc $^{11,12}$.

\section{Feed Efficiency}

The mean values of feed consumed (FC) and feed conversion rate (FCR) are given in table 3 . The mean values of feed consumed by group I, group II, and group III are 466.10 $\pm 22.16,307.57 \pm 13.87$ and $583.19 \pm 6.08$ respectively. And the mean values of FCR in group I, group II, and group III are $4.74 \pm 0.17$, $2.70 \pm 0.25$ and $10 \pm 1.11$ respectively. The results revealed that rice diet showed significantly higher FC and FCR, indicating poor utilization. Spirulina was significantly lower than rice diet indicating better utilization. There was no significant difference was observed between spirulina and stock diets.

The protein content of Spirulina is very high, between $55 \%$ and $77 \%$ by dry weight, depending upon the source. As it contains all essential amino acids, spirulina is a complete protein. Hence the utilization was much higher compared with rice diet which is poor in protein content and poor quality of amino acids ${ }^{13}$.

\section{Biochemical Assay}

The mean values of various serum biochemical parameters like glucose ( $\mathrm{mg} \%)$, Alanine trans elements (IU/L), glucose (mg\%), Cholesterol $(\mathrm{mg} \%)$, triglycerides, urea $(\mathrm{mg} \%)$, calcium $(\mathrm{mg} \%)$,

Table 3: Feed consumed (FC) and feed conversion rate (FCR) of Test diets

\begin{tabular}{lcc} 
Group & FCR & FC \\
\hline Stock diet & $4.74 \pm 0.17$ & $466.1 \pm 22.16$ \\
Spirulina diet & $4.2 \pm 0.45$ & $307.57 \pm 13.87$ \\
Rice diet & $2.39 \pm 0.15$ & $583.19 \pm 6.08$ \\
df & 2,17 & 2,17 \\
F & 20.75 & 79.57 \\
sig & 0 & 0 \\
\hline
\end{tabular}

Values are mean \pm S.E 
Table 4: Protein and albumin levels in different groups of experimental rats

\begin{tabular}{lcc}
\hline Group & Protein & Albumin \\
\hline Stock diet & $7.35 \pm 0.8$ & $2.34 \pm 0.16$ \\
Spirulina diet & $6.95 \pm 0.58$ & $2.48 \pm 0.32$ \\
Rice diet & $6.37 \pm 0.83$ & $1.96 \pm 0.61$ \\
df & 2,16 & 2,16 \\
sig & 0.128 & 0.113 \\
\hline
\end{tabular}

Values are mean \pm S.E

creatinine $(\mathrm{mg} \%)$ in rats fed with stock diet, Spirulina diet and rice based diet are presented in Table 5 and
Fig 1. The mean values of protein ( $\mathrm{g} \%$ ) and albumin ( $\mathrm{g} \%$ ) are presented in Table 4 and Fig 2.

The mean glucose ( $\mathrm{mg} \%$ ) values in group I,II and III were 121.77 $\pm 50.04,107 \pm 33.74$ and $119.73 \pm 20.53$, the mean ALT (IU/L) values were $133.38 \pm 9.11,141.05 \pm 5.29$ and $141.05 \pm 5.33$, the mean cholesterol (mg\%) were $72.08 \pm 15.96$, $75.04 \pm 8.53$ and $46.50 \pm 10.03$, the mean triglyceride $(\mathrm{mg} \%)$ values were $103.86 \pm 60.99,110.36 \pm 60.77$ and $164.15 \pm 53.77$, the mean protein $(\mathrm{mg} \%)$ values were $7.35 \pm 0.80,6.95 \pm 0.58$ and $6.37 \pm 0.83$, the mean albumin $(\mathrm{g} \%)$ were $2.34 \pm 0.16,2.48 \pm 0.32$ and $1.96 \pm 0.61$, the mean urea $(\mathrm{mg} \%)$ values were $22.48 \pm 9.84,24.40 \pm 7.58$ and $8.25 \pm 6.02$, the mean calcium $(\mathrm{mg} \%)$ values were $10.98 \pm 0.98,11.04 \pm 1.42$

Table 5: Serum biochemical parameters in different groups of experimental rats

\begin{tabular}{lccccccccc}
\hline Group & Glucose & ALT & $\begin{array}{c}\text { Chole } \\
\text { sterol }\end{array}$ & $\begin{array}{c}\text { Trigly } \\
\text { cerides }\end{array}$ & $\begin{array}{c}\text { Pro } \\
\text { tein }\end{array}$ & $\begin{array}{c}\text { Albu } \\
\text { min }\end{array}$ & Urea & $\begin{array}{c}\text { Cal } \\
\text { cium }\end{array}$ & $\begin{array}{c}\text { Crea } \\
\text { tinine }\end{array}$ \\
\hline Stock & 121.77 & 133.38 & 72.08 & 103.86 & 7.35 & 2.34 & 22.48 & 10.98 & 1.55 \\
diet & \pm 50.04 & \pm 9.11 & \pm 6.52 & \pm 24.9 & \pm 0.32 & \pm 0.06 & \pm 4.01 & \pm 0.4 & \pm 0.06 \\
Spirulina & 107.7 & 141.05 & 75.04 & 110.36 & 6.95 & 2.48 & 24.4 & 11.04 & 1.56 \\
diet & \pm 33.74 & \pm 5.29 & \pm 3.49 & \pm 24.05 & \pm 0.24 & \pm 0.12 & \pm 3.09 & \pm 0.58 & \pm 0.72 \\
Rice & 119.73 & 141.05 & 46.5 & 164.15 & 6.37 & 1.96 & 8.26 & 9.52 & 2.59 \\
diet & \pm 20.53 & \pm 5.33 & \pm 4.48 & \pm 24.8 & \pm 0.37 & \pm 0.27 & \pm 2.69 & \pm 1.16 & \pm 0.07 \\
df & 2,17 & 2,17 & 2,17 & 2,17 & 2,17 & 2,17 & 2,17 & 2,17 & 2,17 \\
sig & 0.778 & 0.113 & 0.003 & 0.408 & 0.128 & 0.113 & 0.11 & 0.298 & 0.873 \\
\hline
\end{tabular}

Values are mean \pm S.E

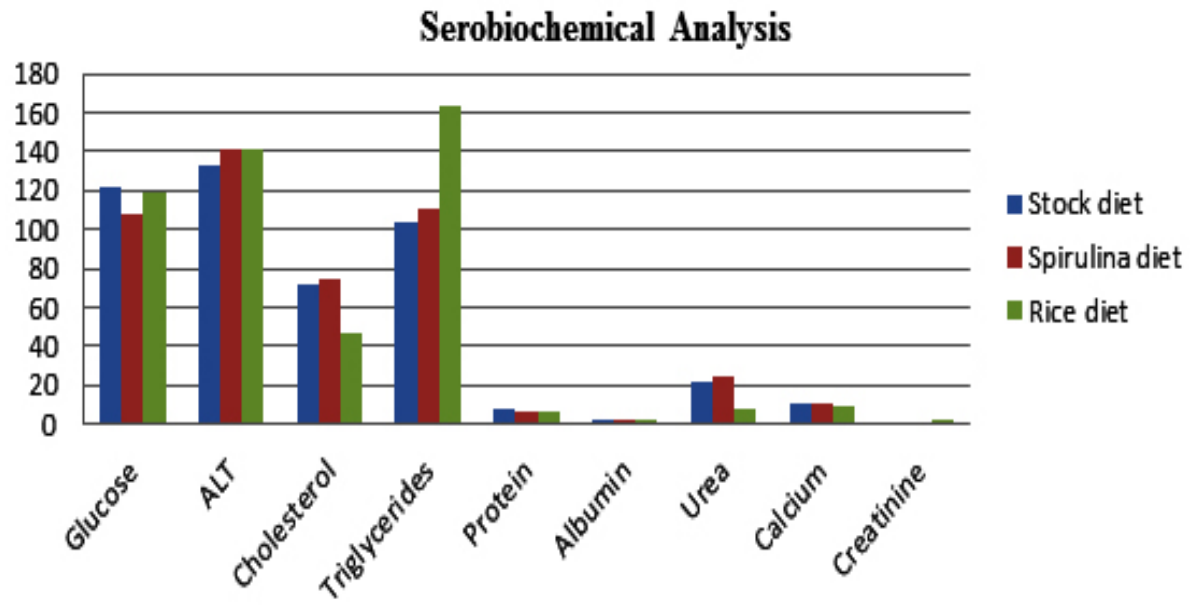

Fig. 1: Serum biochemical parameters in different groups of experimental rats 


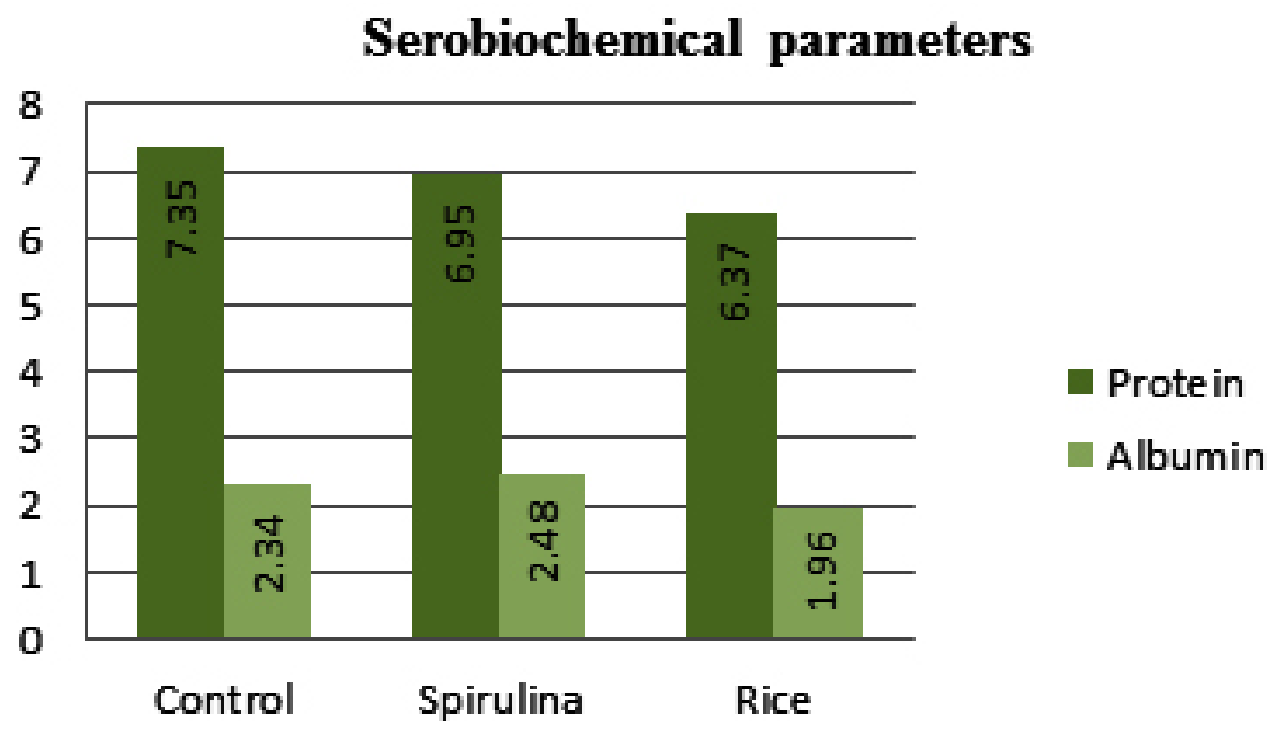

Fig. 2: serum protein and albumin levels in different groups of experimental rats

and $9.52 \pm 2.60$ and the mean creatinine values were $1.55 \pm 0.06,1.56 \pm 0.72$ and $2.59 \pm 0.07$ respectively. There was no significant $(p<0.05)$ difference between sero-biochemical parameters except in cholesterol and urea in Group I and II, where as in group III cholesterol and urea levels were very low compared to group I and group II.

The decrease in cholesterol by rice could be due to lack of cholesterol in foods from plant origin and moderate to high PUFA content which might caused decrease in serum cholesterol. Such a reduction in cholesterol level is attributed to the significant amounts of PUFA present in rice, which gets incorporated into and consequently weakens cell membranes when insufficient saturated fats are not available $(15,16)$. Decrease in urea concentration could be attributed to the low crude protein content in rice diet (6-7\%) and poor amino acid profile (17).

\section{CONCLUSION}

Spirulina has a high concentration of nutrients. It provides remarkable health benefits to malnourished people. The complete protein in Spirulina promotes growth, development and nutritional improvement in infant and children. It not only promotes growth, overall health and nutrition, it has been shown to lower cholesterol and has the ability to boost the immune system. As it contains a number of nutrients as well as many functional components, it is being recognized as a super food and efforts are being made to incorporate spirulina in medical, functional and therapeutic foods. In conclusion, Spirulina may play a beneficial role in promoting growth, preventing disease, improving nutritional status and maintaining health and wellness.

\section{REFERENCES}

1. Hasler C. M. Functional Foods: Their Role in Disease Prevention and Health Promotion. Food technology-Champaign Then Chicago; 52(63): 147: (1998).

2. Scalbert A, Manach C, Morand C, Rémésy
C, Jiménez L. Dietary Polyphenols and The Prevention of Diseases. Critical Reviews in Food Science and Nutrition; 45(4): 287-306: (2005)

3. Liu S, Willett W. C, Stampfer M. J, Hu F. B, 
Franz M, Sampson L., ... Manson J. E. A Prospective Study of Dietary Glycemic load, Carbohydrate Intake, and Risk of Coronary Heart Disease in US Women. The American Journal of Clinical Nutrition; 71(6): 1455-1461: (2000).

4. Belay, A, Ota Y, Miyakawa K, Shimamatsu H. Current Knowledge on Potential Health Benefits of Spirulina. Journal of Applied Phycology, 5(2): 235-241: (1993).

5. Khan Z, Bhadouria P, Bisen P. S. Nutritional and Therapeutic Potential of Spirulina. Current Pharmaceutical Biotechnology; 6(5): 373-379: (2005).

6. Patel S, Goyal A. Current and Prospective Insights on Food and Pharmaceutical Applications of Spirulina. Current Trends in Biotechnology and Pharmacy; 7(2): 681-695: (2013).

7. Borowitzka M. A. High-Value Products from Microalgae-Their Development and Commercialisation. Journal of Applied Phycology, 25(3): 743-756: (2013).

8. Association of Official Analytical Chemists. Official Methods of Analysis (Vol. 534). W. Horwitz (Ed.). Arlington, VA, Washington DC: AOAC.

9. Upton R. A. Simple and Reliable Method for Serial Sampling of Blood from Rats. Journal of Pharmaceutical Sciences; 64(1): 112-114: (1975).

10. Dillon J. C, Phuc A. P, Dubacq J. P. Nutritional Value of the Alga Spirulina. In Plants in Human
Nutrition (pp. 32-46). Karger Publishers: (1995).

11. De Oliveira M. A. C. L, Monteiro M. P. C, Robbs P. G, Leite S. G. F. Growth and Chemical Composition of Spirulina Maxima and Spirulina Platensis Biomass at Different Temperatures. Aquaculture International; 7(4): 261-275: (1999).

12. Colla L. M, Bertolin T. E, Costa J. A. V. Fatty Acids Profile of Spirulina Platensis Grown Under Different Temperatures and Nitrogen Concentrations. Zeitschrift Für Naturforschung C; 59(1-2): 55-59: (2004).

13. Clement G, Giddey C, Menzi R. Amino Acid Composition and Nutritive Value of The Alga Spirulina maxima. Journal of the Science of Food and Agriculture; 18(11): 497-501: (1967).

14. Morita T, Oh-hashi A, Takei K, Ikai M, Kasaoka S, Kiriyama S. Cholesterol-lowering Effects of Soybean, Potato and Rice Proteins Depend on Their low Methionine Contents in Rats Fed a Cholesterol-Free Purified diet. The Journal of Nutrition; 127(3): 470-477: (1997).

15. Ohvo-Rekilä H, Ramstedt B, Leppimäki $P$, Slotte J. P. Cholesterol Interactions With Phospholipids in Membranes. Progress in Lipid Research; 41(1): 66-97: (2002).

16. Radford E. P. Factors Modifying Water Metabolism in Rats Fed Dry Diets. American Journal of Physiology-Legacy Content; 196(5): 1098-1108: (1959). 